\title{
Analysis of the Seasonality of Births in a Large Cohort of Patients with Thyroid Hemiagenesis - A Preliminary Study
}

\author{
Ewelina Szczepanek-Parulska, ${ }^{1,}$ Ariadna Zybek-Kocik, ${ }^{1}$ Marta Fichna, ${ }^{1,2}$ Marek Niedziela, ${ }^{3}$ Agata \\ Czarnywojtek, ${ }^{1,4}$ Paulina Fularz, ${ }^{1}$ Michal Michalak, ${ }^{5}$ Jerzy Moczko, ${ }^{5}$ and Marek Ruchala ${ }^{1}$ \\ ${ }^{1}$ Department of Endocrinology, Metabolism and Internal Medicine, Poznan University of Medical Sciences, Poznan, Poland \\ ${ }^{2}$ Institute of Human Genetics, Polish Academy of Sciences, Poznan, Poland \\ ${ }^{3}$ Department of Paediatric Endocrinology and Rheumatology, Poznan University of Medical Sciences, Poznan, Poland \\ ${ }^{4}$ Department of Pharmacology, Poznan University of Medical Sciences, Poznan, Poland \\ ${ }^{5}$ Department of Computer Science and Statistics, Poznan University of Medical Sciences, Poznan, Poland \\ "Corresponding author: Ewelina Szczepanek-Parulska, MD, PhD, Department of Endocrinology, Metabolism and Internal Medicine, Poznan University of Medical Sciences, \\ Poznan, Poland. Tel: +48-8691330, E-mail: ewelinaparulska@gmail.com
}

Received 2017 September 05; Revised 2018 February 17; Accepted 2018 February 23.

\begin{abstract}
Objectives: Thyroid hemiagenesis (THA) is a congenital anomaly of unknown origin. The aim of this study was to assess for the first time whether there is any seasonality in the date of birth of patients with THA in comparison to general population.

Methods: The studied group consisted of 105 patients with THA. The control data regarding total live births in Poland were derived from the Polish Statistical Annals ( $n=2421384$ ). Both groups were subdivided according to the month of birth, season of birth and quarter of the year.

Results: Analysis of the months of birth revealed that patients with THA were born significantly less often in October than control subjects $(\mathrm{P}=0.0217)$. Although a trend is observed, that more patients with THA were born in the 1st quarter of the year and in winter, while THA patients were less often born in autumn or in 4th quarter of the year, the difference did not reach statistical significance. Conclusions: Month of birth may exert some effect on the risk of developing THA. Studies on larger cohorts are needed to confirm the observation. The results suggest a potential modifying effect of environmental factors in the pathogenesis of THA.
\end{abstract}

Keywords: Thyroid Hemiagenesis, Thyroid Dysgenesis, Date of Birth, Seasonality, Environmental Factors

\section{Background}

Thyroid hemiagenesis (THA) is a rare congenital developmental abnormality, where one of the thyroid lobes fails to develop (1). The etiology of THA and other thyroid dysgenesis (TD) is largely unknown $(2,3)$. Thus, factors that disturb the process by influencing the lobulation of the thyroid anlage are yet to be unraveled $(4,5)$. Although the occurrence of THA and other TD in families suggests a genetic background (6), THA usually occurs as sporadic condition (7). The process of thyroid bilobation lasts until $10-12^{\text {th }}$ week of gestation (8). Thus, the exposure of the pregnant women to some environmental factor in the first trimester might disturb that process.

The process of thyroid bilobation proceeds in parallel with the development of the blood vessels from the third pharyngeal arch (9). A recent report demonstrated by CTAngiography agenesis of the thyroid artery on the agenetic side in patients with THA. Therefore, the lack of one thyroid lobe may result from inadequate blood supply at early stages of embryogenesis (10). We cannot rule out a role of other unknown factors, which may modulate expression of the final phenotype. Overall, it seems probable that TD results from a complex interplay between genetic and environmental factors (1).

An interesting and promising concept was that environmental factors during pregnancy might interrupt the thyroid embryogenesis, and therefore result in a misdevelopment of the fetal thyroid gland. However, data from previous studies on association between the season of birth and the incidence of TD (mainly agenesis and ectopy) causing congenital hypothyroidism ( $\mathrm{CH}$ ) are conflicting (11-19). So far, seasonality of birth have been linked to several autoimmune endocrine diseases $(13,20-22)$. To date, seasonality of births have not been analyzed in regard to the presence of THA yet. Thus, the aim of this study was to assess whether there is any preference for seasonality in the dates of birth of patients with THA in comparison to general population. 


\section{Methods}

\subsection{Patients}

The studied group consisted of 105 consecutive patients diagnosed with THA at two academic tertiary reference centers in the years 2008 - 2016. There were 14 men and 91 women, aged 2 - 80 years. The median age at diagnosis was 28 years old for women and 34 for men. The diagnosis of THA was initially made by thyroid ultrasound examination and then confirmed by thyroid I131 scintiscan. The diagnosis of THA was established when one of the thyroid lobes or lobe with isthmus could not be visualized on ultrasound examination. Patients following thyroidectomy, radioiodine therapy or autoimmune destructive thyroiditis were excluded from analysis. Absence of the lobe was confirmed by demonstration of a unilateral isotope uptake on thyroid I131 scintiscan. One thyroid lobe hypoplasia or other types of TD constituted the exclusion criteria. The control data regarding total live births in Poland were derived from the Polish Statistical Annals for the years 1980, 1990, 2000, 2010, and 2012 ( $n=2421384$ ).

\subsection{Methods}

All procedures performed in our study were in accordance with the ethical standards of our institutional Bioethical Committee of Poznan University of Medical Sciences and with the 1964 Helsinki declaration and its later amendments or comparable ethical standards. An informed consent was obtained from all individual participants included in the study after full explanation of the purpose and nature of all procedures used.

The dates of birth of patients diagnosed with THA were analyzed and compared to the dates of birth for the Polish population. Both groups were subdivided according to the month of birth, season of birth (spring, summer, autumn, winter) and quarter ( 1 - 4) of the year. The seasons of the year in the study were established as follows: spring (March, April, May), summer (June, July, August), autumn (September, October, November) and winter (December, January, February). The quarters of the year were defined accordingly: $1^{\text {st }}$ (January, February, March,), $2^{\text {nd }}$ (April, May, June), $3^{\text {rd }}$ (July, August, September) and $4^{\text {th }}$ (October, November, December). The differences between the groups were analyzed statistically. Statistical analysis was conducted using MedCalc version 16.8.4. (MedCalc software bvba) and TSA Cosinor software (Expert Soft Technologie). Month-by-month variation was screened for using chi-square test for independece, with odds ratios (ORs) and 95\% confidence intervals (CIs) calculated, to compare the birth rates for each month in subjects with THA and the control population. A Cosinor model was used to estimate the annual seasonal trend in the month-of-birth distribution across all 12 months. A P-value of less than 0.05 was regarded as significant.

\section{Results}

A percentage of patients with THA and control subjects born in particular months of the year as well as observed differences are presented in Table 1 . Odds ratios (OR) and 95\% confidence interval (CI) values for the chance to be born in particular month for the patients with THA were presented in Figure 1. An analysis of the months of birth revealed that patients with THA were born significantly less often in October than control subjects $(\mathrm{P}=0.0217)$. Furthermore, a studied THA population was tested using Cosinor model, however the observed variations in the dates of birth were considered not significant $(\mathrm{P}=0.3714)$.

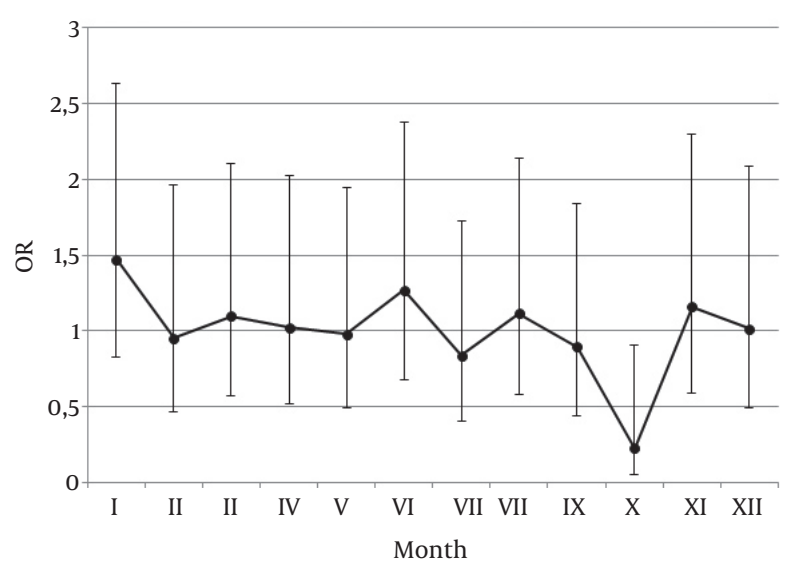

Figure 1. Odds ratios (OR) for the probability to be born in particular months for patients with THA

Moreover, a separate analysis was performed when patients were divided according to the quarters of the year. There were: 31 patients with THA born in the $1^{\text {st }}$ quarter, 29 born in the $2^{\text {nd }}$ quarter, 26 born in the $3^{\text {rd }}$ quarter and 19 born in the $4^{\text {th }}$ quarter. If the seasons of the year are concerned: 29, 28, 29 and 19 patients with THA were born in winter, spring, summer and autumn, respectively. Although a trend is observed, that more patients with THA were born in the 1st quarter of the year (Figure $2 \mathrm{~A}$ ) and in winter (Figure 2B), while THA patients were less often born in autumn or in 4th quarter of the year, the difference did not reach statistical significance. 


\begin{tabular}{|c|c|c|c|c|c|c|}
\hline Months of Birth & Control Subjects (\%) & THA Patients (\%) & $\mathbf{O R}^{\mathbf{a}}$ & \multicolumn{2}{|c|}{$95 \% \mathrm{CI}^{\mathrm{a}}$} & PValue \\
\hline I & 8.76 & 12.38 & 1.47 & 0.82 & 2.63 & 0.1891 \\
\hline II & 7.96 & 7.62 & 0.95 & 0.46 & 1.96 & 0.8975 \\
\hline II & 8.76 & 9.52 & 1.10 & 0.57 & 2.10 & 0.7818 \\
\hline $\mathbf{V}$ & 8.73 & 8.57 & 0.98 & 0.49 & 1.94 & 0.9540 \\
\hline VI & 8.43 & 10.48 & 1.27 & 0.68 & 2.37 & 0.4504 \\
\hline VII & 8.95 & 7.62 & 0.84 & 0.41 & 1.73 & 0.6325 \\
\hline VII & 8.62 & 9.52 & 1.12 & 0.58 & 2.14 & 0.7405 \\
\hline IX & 8.43 & 7.62 & 0.90 & 0.44 & 1.84 & 0.7658 \\
\hline $\mathbf{x}$ & 7.97 & 1.90 & 0.22 & 0.06 & 0.91 & 0.0217 \\
\hline XI & 7.49 & 8.57 & 1.16 & 0.58 & 2.29 & 0.6730 \\
\hline XII & 7.51 & 7.62 & 1.02 & 0.49 & 2.09 & 0.9675 \\
\hline
\end{tabular}

Abbreviations: OR, odds ratios; $\mathrm{CI}$, confidence interval.

${ }^{\mathrm{a}}$ Values for the Chance to be Born in Particular Month for the Patients with THA and Control Subjects.

\section{Discussion}

Several studies on the association between the month or season of birth and the risk for TD have been conducted so far. However, it mainly included patients diagnosed with $\mathrm{CH}$, presenting either thyroid ectopy, agenesis or severe thyroid hypoplasia. To date, such an analysis has never been performed for patients with THA. Similarly to our cohort, the anomaly is usually detected incidentally in adulthood (1). Hence, collection of a large cohort of patients with THA is challenging. Severe types of TD result from disturbances of thyroid primordial development or downward migration. However, whether the same factors influence thyroid bilobation remains unknown.

So far conducted studies on the association of birth season and the risk of TD provide conflicting results, likewise the data on the period of a year predisposing to the development of TD. One of the first large cohort studies reporting a seasonal variation in the incidence of $\mathrm{CH}$ was performed in Finland by Virtanen et al. (19). The study on Japanese population by Nakamizo et al. in a - similar to ours - group of 108 patients, revealed the highest incidence of $\mathrm{CH}$ in February, and the lowest in May (16). In our cohort, the highest incidence of THA was noted in January, and the lowest in October. The number of $\mathrm{CH}$ patients born in winter (December-February) was the largest among the four seasons, if compared to spring or autumn (16). These results are in accordance with our observations for THA. Miyai et al. analyzed newborns with $\mathrm{CH}$ caused by TD in a period of 14 years, and the incidence of $\mathrm{CH}$ appeared significantly higher in late autumn (from October to December) (15). These results stay in contrast to our study, as we observed the lowest incidence of THA in this period of the year. What is interesting, in the study by Miyai et al. the prevalence of dysgenetic $\mathrm{CH}$ was found to be higher about 9 - 10 months following the emergence of influenza. Authors speculated that this might be related to the maternal viral infection.

Another study performed on the British population of 1128632 live newborns over a period of 16 years demonstrated a significantly increased (1:2323 live births) incidence of $\mathrm{CH}$ between October and December, if compared to average 1:2924 (12). In contrast, higher incidence of $\mathrm{CH}$ was observed in the Japanese population between May and July in the years 1957 -1976, and for October-December for the next five years (14). These results are in contrast to our findings, where October was the month of the lowest incidence of THA.

On the other hand, several authors were not able to find any relationship between the date of birth and the incidence of TD. Rosenthal et al. did not demonstrate seasonal variability in the incidence of $\mathrm{CH}$ in the study on North-West England population (18). The conclusions were consistent with the Dutch research (17). In the recent paper by Deladoey et al. a cohort of 424 subjects diagnosed with $\mathrm{CH}$ due to TD in a period of 16 years was analyzed and the distribution of the months of birth was accidental, without any preponderance to particular season of the year (11).

The impact of the month-of-birth on the risk of several diseases has been studied also for autoimmune disorders, including Addison disease, or type 1 diabetes, with the risky period of a year in autumn/winter months (13, 20-22). Possible explanations for such an asymmetric distribution of 
A

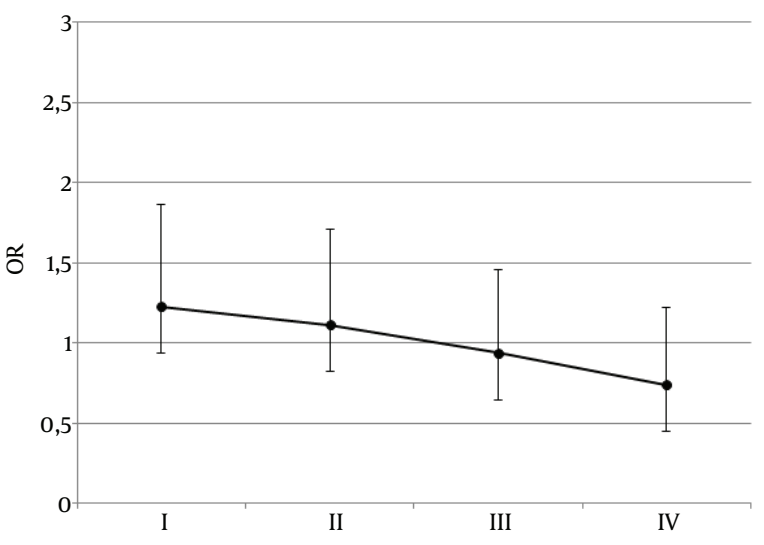

B

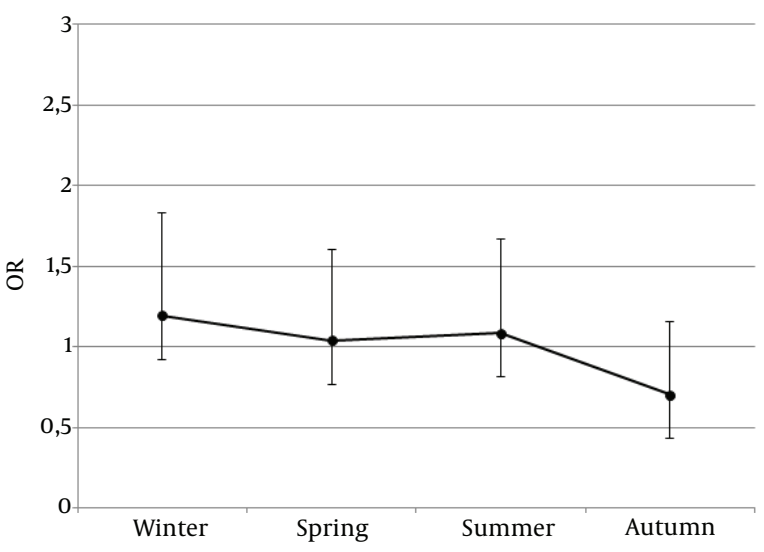

Figure 2. Odds ratios (OR) for the probability to be born in particular quarter (A) and the season (B) of the year for patients with THA

the dates of birth include the influence of seasonal maternal viral infections or vitamin D deficiency on the developing progeny's innate immune system (23). It is also suspected that hitherto undefined environmental factor of seasonal appearance may affect the process of organogenesis, including the development of the thyroid gland.

On the other hand, cases of familial occurrence of different TD including THA and reported discordance of monozygotic twins if the thyroid morphology is concerned, may argue against the dominant role of environmental factors in the pathogenesis of thyroid developmental disturbances $(24,25)$. However, still the modifying impact cannot be ruled out.

In interpretation of our findings we need to note potential limitations of our study. The incidence of THA varies according to different studies and is estimated at 0.05 $0.5 \%$ of the general population (1). However, due to its rel- atively oligosymptomatic course, it is usually detected incidentally. Although our group of patients with THA is the largest reported to date, from the statistical point of view our sample size is still relatively small, what might potentially limit the power of the study. Secondly, the subjects in our study were not recruited from a formal national or regional registry, and represent consecutive patients diagnosed at two tertiary reference centres. This could potentially be the reason for a bias. Moreover, in majority of patients we were not able to verify whether they were born at term. Lastly, our controls obtained from the Polish Statistical Annals inevitably include subjects with THA. However, given the rarity of the disease, the expected number of THA cases in the control population is probably too small to affect the results. The gender distribution of our cohort of patients with THA is also different from that of general population. However, it does not seem to importantly influence the results.

\subsection{Conclusions}

To the best of authors' knowledge, this is the first analysis of birth seasonality performed on a group of patients with THA. Our study demonstrates that month of birth may exert some effect on the risk of developing THA. Although a trend is observed that more patients with THA were born in the 1st quarter of the year and in winter, while THA patients were less often born in autumn or in 4 th quarter of the year, the difference did not reach statistical significance. Studies on larger cohort of subjects are needed to confirm the observation. The results suggest a potential modifying effect of environmental factors in the pathogenesis of THA. The exact factor remains unknown and further studies are warranted to provide an explanation for the observed phenomenon. Identification of environmental factors potentially disturbing the normal thyroid development would allow proposing methods of prevention.

\section{References}

1. Szczepanek-Parulska E, Zybek-Kocik A, Wartofsky L, Ruchala M. Thyroid Hemiagenesis: Incidence, Clinical Significance, and Genetic Background. J Clin Endocrinol Metab. 2017;102(9):3124-37. doi: 10.1210/jc.2017-00784. [PubMed: 28666345].

2. Lotfi MH, Rahimi Pordanjani S, Akhondi-Meybodi M. Five-Year Follow Up of Physical Growth and Thyroid Hormone Levels in Infants With Congenital Hypothyroidism. Iran J Pediatr. 2017;27(1). e5690.

3. Rahmani K, Yarahmadi S, Etemad K. Importance of Early Treatment in Congenital Hypothyroidism. Iran J Pediatr. 2017;27(3). e9438.

4. Szczepanek E, Ruchala M, Szaflarski W, Budny B, Kilinska L, Jaroniec M, et al. FOXE1 polyalanine tract length polymorphism in patients with thyroid hemiagenesis and subjects with normal thyroid. Horm Res Paediatr. 2011;75(5):329-34. doi:10.1159/000322874. [PubMed: 21311165].

5. Szczepanek-Parulska E, Szaflarski W, Piatek K, Budny B, JaszczynskaNowinka K, Biczysko M, et al. Alternative 3' acceptor site in the exon 2 of human PAX8 gene resulting in the expression of unknown mRNA 
variant found in thyroid hemiagenesis and some types of cancers. Acta Biochim Pol. 2013;60(4):573-8. [PubMed: 24340305].

6. Budny B, Szczepanek-Parulska E, Zemojtel T, Szaflarski W, Rydzanicz M, Wesoly J, et al. Mutations in proteasome-related genes are associated with thyroid hemiagenesis. Endocrine. 2017;56(2):279-85 doi: 10.1007/s12020-017-1287-4. [PubMed: 28390009]. [PubMed Central: PMC5395596].

7. Kizys MM, Nesi-Franca S, Cardoso MG, Harada MY, Melo MC, Chiamolera MI, et al. The absence of mutations in homeobox candidate genes HOXA3, HOXB3, HOXD3 and PITX2 in familial and sporadic thy roid hemiagenesis. J Pediatr Endocrinol Metab. 2014;27(3-4):317-22. doi: 10.1515/jpem-2013-0289. [PubMed: 24127533].

8. Ruchala M, Szczepanek E, Sujka-Kordowska P, Zabel M, Biczysko M, Sowinski J. The immunohistochemical demonstration of parafollicular cells and evaluation of calcium-phosphate balance in patients with thyroid hemiagenesis. Folia Histochem Cytobiol. 2011;49(2):299305. [PubMed: 21744332]

9. Fagman H, Andersson L, Nilsson M. The developing mouse thyroid: embryonic vessel contacts and parenchymal growth pattern during specification, budding, migration, and lobulation. Dev Dyn. 2006;235(2):444-55. doi:10.1002/dvdy.20653. [PubMed: 16331648].

10. Verma A, Bhartiya SK, Basu SP, Shukla VK, Shukla RC. Congenital thyroid hemiagenesis with thyroid nodules-Role of TI-RADS to prevent long term thyroid replacement therapy. Int J Surg Case Rep. 2016;27:5962. doi: 10.1016/j.ijscr.2016.07.055. [PubMed: 27544726]. [PubMed Central: PMC4995530].

11. Deladoey J, Belanger N, Van Vliet G. Random variability in congenital hypothyroidism from thyroid dysgenesis over 16 years in Quebec. J Clin Endocrinol Metab. 2007;92(8):3158-61. doi: 10.1210/jc.2007-0527. [PubMed: 17504897].

12. Hall SK, Hutchesson AC, Kirk JM. Congenital hypothyroidism, seasonality and consanguinity in the West Midlands, England. Acta Paediatr. 1999;88(2):212-5. [PubMed: 10102157].

13. Hamilton A, Newby PR, Carr-Smith JD, Disanto G, Allahabadia A, Armitage $\mathrm{M}$, et al. Impact of month of birth on the development of autoimmune thyroid disease in the United Kingdom and Europe. $J$ Clin Endocrinol Metab. 2014;99(8):E1459-65. doi: 10.1210/jc.2014-1270. [PubMed: 24840812].

14. Miyai K, Connelly JF, Foley TP Jr, Irie M, Illig R, Lie SO, et al. An analysis of the variation of incidence of congenital dysgenetic hypothyroidism in various countries. Endocrinol Jpn.1984;31(1):77-81. [PubMed: 6734525].
15. Miyai K, Inaoka K, Miyagi T, Committee for N, Infant Screening in O. Further studies on episodic occurrence of congenital dysgenetic hypothyroidism in Osaka, Japan. EndocrJ. 2005;52(5):599-603. [PubMed: 16284439].

16. Nakamizo M, Toyabe S, Asami T, Akazawa K. Seasonality in the incidence of congenital hypothyroidism in Japan.J Paediatr Child Health. 2005;41(7):390-1. doi: 10.1111/j.1440-1754.2005.00644_1.x. [PubMed: 16014151].

17. Reijneveld SA, Verkerk PH. No evidence for seasonality of congenital hypothyroidism in The Netherlands. Acta Paediatr. 1993;82(2):212-3.

18. Rosenthal M, Addison GM, Price DA. Congenital hypothyroidism: increased incidence in Asian families. Arch Dis Child. 1988;63(7):790-3. [PubMed: 3415295]. [PubMed Central: PMC1779081].

19. Virtanen M, Maenpaa J, Pikkarainen J, Pitkanen L, Perheentupa J. Aetiology of congenital hypothyroidism in Finland. Acta Paediatr Scand. 1989;78(1):67-73. [PubMed: 2919526].

20. Kahn HS, Morgan TM, Case LD, Dabelea D, Mayer-Davis EJ, Lawrence JM, et al. Association of type 1 diabetes with month of birth among U.S. youth: The SEARCH for Diabetes in Youth Study. Diabetes Care. 2009;32(11):2010-5. doi: 10.2337/dc09-0891. [PubMed: 19675199]. [PubMed Central: PMC2768213].

21. Krassas GE, Tziomalos K, Pontikides N, Lewy H, Laron Z. Seasonality of month of birth of patients with Graves' and Hashimoto's diseases differ from that in the general population. Eur J Endocrinol. 2007;156(6):631-6. doi: 10.1530/EJE-07-0015. [PubMed: 17535862].

22. Pazderska A, Fichna M, Mitchell AL, Napier CM, Gan E, Ruchala M, et al. Impact of Month of Birth on the Risk of Development of Autoimmune Addison's Disease. J Clin Endocrinol Metab. 2016;101(11):42148. doi: 10.1210/jc.2016-2392. [PubMed: 27575942]. [PubMed Central: PMC5095257]

23. Fisman D. Seasonality of viral infections: mechanisms and unknowns. Clin Microbiol Infect. 2012;18(10):946-54. doi: 10.1111/j.14690691.2012.03968.x. [PubMed: 22817528].

24. Kuehnen P, Grueters A, Krude H. Two puzzling cases of thyroid dysgenesis. Horm Res. 2009;71 Suppl 1:93-7. doi: 10.1159/000178047. [PubMed: 19153515].

25. Perry R, Heinrichs C, Bourdoux P, Khoury K, Szots F, Dussault JH, et al. Discordance of monozygotic twins for thyroid dysgenesis: implications for screening and for molecular pathophysiology. $J$ Clin Endocrinol Metab. 2002;87(9):4072-7. doi: 10.1210/jc.2001-011995. [PubMed: 12213848]. 